\title{
Promoting Broad and Stable Improvements in Low-Income Children's Numerical Knowledge Through Playing Number Board Games
}

\author{
Geetha B. Ramani \\ University of Maryland
}

\author{
Robert S. Siegler \\ Carnegie Mellon University
}

\begin{abstract}
Theoretical analyses of the development of numerical representations suggest that playing linear number board games should enhance young children's numerical knowledge. Consistent with this prediction, playing such a game for roughly $1 \mathrm{hr}$ increased low-income preschoolers' (mean age $=5.4$ years) proficiency on 4 diverse numerical tasks: numerical magnitude comparison, number line estimation, counting, and numeral identification. The gains remained 9 weeks later. Classmates who played an identical game, except for the squares varying in color rather than number, did not improve on any measure. Also as predicted, home experience playing number board games correlated positively with numerical knowledge. Thus, playing number board games with children from low-income backgrounds may increase their numerical knowledge at the outset of school.
\end{abstract}

Children vary greatly in the mathematical knowledge they possess when they enter school. These differences in initial mathematical knowledge appear to have large, long-term consequences. Proficiency in mathematics at the beginning of kindergarten is strongly predictive of mathematics achievement test scores years later: in elementary school, in middle school, and even in high school (Duncan et al., 2007; Stevenson \& Newman, 1986). This pattern is consistent with the general finding that initial knowledge is positively related to learning (Bransford, Brown, \& Cocking, 1999), but the relations in math are unusually strong and persistent. For example, they were considerably stronger than the relations between initial and subsequent reading proficiency in the same six longitudinal studies reviewed by Duncan et al. (2007; average standardized beta coefficients of .34 vs. .16).

Given the strong and persistent relation between early and later mathematical proficiency, it is especially unfortunate that preschoolers and kindergartners from low-income families enter school with far less numerical knowledge than peers from more affluent families. Being clear on the locus of this gap is crucial for understanding it. On nonverbal numerical

This research was supported by Department of Education Grants R305H020060 and R305H050035. We would like to thank the Allegheny Intermediate Unit Head Start classrooms and the Carnegie Mellon Children's School for their participation in this research. Special appreciation is also extended to Mary Wolfson and Jenna Zonneveld for their assistance with data collection and coding.

Correspondence concerning this article should be addressed to Geetha B. Ramani, Department of Human Development, University of Maryland, College Park, MD 20742, or Robert S. Siegler, Department of Psychology, Carnegie Mellon University, Pittsburgh,PA 15213. Electronic mail may be sent to gramani@umd. edu or rs7k@andrew.cmu.edu. tasks, the performance of young children from lowincome backgrounds is equivalent to that of age peers from wealthier backgrounds (Ginsburg \& Russell, 1981; Jordan, Huttenlocher, \& Levine, 1992; Jordan, Levine, \& Huttenlocher, 1994). However, on tasks with verbally stated or written numerals, the same studies and many others find large differences. This is the type of numerical knowledge at issue in the present study.

Substantial differences in the numerical proficiency of preschoolers and kindergartners from different socioeconomic status backgrounds have been demonstrated on a wide range of foundational tasks: reciting the counting string, counting sets of objects, counting up or down from a given number other than 1 , recognizing written numerals, adding and subtracting, and comparing numerical magnitudes (Ginsburg \& Russell, 1981; Griffin, Case, \& Siegler, 1994; Jordan, Kaplan, Olah, \& Locuniak, 2006; Jordan et al., 1992, 1994; Saxe, Guberman, \& Gearhart, 1987; Starkey, Klein, \& Wakeley, 2004; Stipek \& Ryan, 1997). The early differences in numerical proficiency tend to become even more pronounced as children progress through school (Alexander \& Entwisle, 1988; Geary, 1994, 2006). It thus seems vitally important to analyze the sources of these differences in early numerical understanding and to use the analyses to formulate methods for helping low-income preschoolers gain numerical knowledge. Doing so may help prevent the early differences between children from low- and middle-income families from growing into larger, less tractable, later ones.

\footnotetext{
(C) 2008, Copyright the Author(s)

Journal Compilation (C) 2008, Society for Research in Child Development, Inc. All rights reserved. 0009-3920/2008/7902-0009
} 


\section{Theoretical Background}

Studies using a variety of methods, including multidimensional scaling, chronometric analysis, and error analysis, indicate that people represent numerical magnitudes in multiple ways (Banks \& Coleman, 1981; Holyoak \& Mah, 1982; Shepard, Kilpatrick, \& Cunningham, 1973; Siegler \& Opfer, 2003). Two particularly prominent forms are the logarithmic ruler and linear ruler representations. Within the logarithmic ruler representation (Dehaene, 1997), subjective magnitude is a natural logarithmic function of objective magnitude. In contrast, within the linear ruler representation (Case \& Okamoto, 1996), subjective magnitude is a linear function of objective magnitude.

Increasing reliance on linear representations of numbers seems to play a central role in the development of numerical knowledge. This pattern can be illustrated on a number line estimation task that involves presenting lines with a number at each end (e.g., 0 and 100) and no other numbers or marks inbetween; the goal is to estimate the location on the line of a third number written above the line (e.g., "Where would 74 go?"). An advantage of this task is that it transparently reflects the ratio characteristics of the number system. Just as 80 is twice as large as 40 , the estimated location of 80 should be twice as far from 0 as the estimated location of 40 . More generally, estimated magnitude $(y)$ should increase linearly with actual magnitude $(x)$, with a slope of 1.00 , as in the equation: $y=x$.

Often, however, children's estimates do not increase linearly with numerical magnitude; instead, the estimates initially increase logarithmically. The change from logarithmic to linear representations occurs at different times for different numerical ranges. On 0-100 number lines, kindergartners consistently produce estimates that parallel the hypothesized logarithmic ruler representation, whereas second graders produce estimates that parallel the hypothesized linear ruler representation (Siegler \& Booth, 2004). A similar change occurs on $0-1,000$ number lines between second and fourth grades, with second graders' estimates fitting the logarithmic ruler model and fourth graders' and older children's fitting the linear ruler model (Booth \& Siegler, 2006; Opfer \& Siegler, 2007; Siegler \& Opfer, 2003). Individual children often produce linearly increasing patterns of estimates on smaller numerical scales (e.g., 0-100) and logarithmically increasing ones on larger scales (e.g., $0-1,000)$. Thus, the change, at least between kindergarten and fourth grade, seems to reflect growing experience with numbers in a given range rather than more abstract understanding of the base-10 system, which presumably would generalize to any scale.

This age-related change in number line estimation is not an isolated phenomenon. Children undergo parallel changes from logarithmic to linear representations of numerical magnitude at the same ages on at least two other estimation tasks: numerosity estimation (generating approximately $N$ dots on a computer screen, where 0 and 1,000 dots are shown) and measurement estimation (drawing a line of approximately $N$ units, where lines of 1 and 1,000 units are shown; Booth \& Siegler, 2006). Consistent individual differences are also present on these tasks, with most children within each grade from kindergarten through fourth grade producing either linear estimation patterns on all three tasks or logarithmic patterns on all three (Booth \& Siegler, 2006). Linearity of number line estimates also correlates positively with accuracy of magnitude comparison (Siegler \& Laski, 2007), learning of answers to unfamiliar addition problems (Booth, 2005), and overall math achievement test scores (Booth \& Siegler, 2006; Siegler \& Booth, 2004). Within-grade correlations between linearity of estimates on each of the three estimation tasks and math achievement test scores are substantial, typically between $r=.50$ and $r=.60$.

The numerical experiences that lead to initial formation of linear representations of very small numbers $(0-10)$ are unknown. It seems likely that counting experience during the preschool period contributes, but such experience appears insufficient to create linear representations of the numbers' magnitudes. Children often can count perfectly in a numerical range more than a year before they generate linear representations of numerical magnitudes in that range (Schaeffer, Eggleston, \& Scott, 1974; Siegler \& Ramani, in press).

If counting experience is insufficient to yield linear magnitude representations, what other numerical experiences might contribute? One common activity that seems ideally designed for producing linear representations is playing linear, numerical, board games - that is, board games with linearly arranged, consecutively numbered, equal-size spaces (e.g., Chutes and Ladders). As noted by Siegler and Booth (2004), such board games provide multiple cues to both the order of numbers and the numbers' magnitudes. In such games, the greater the number in a square, the greater (a) the distance that the child has moved the token, (b) the number of discrete moves the child has made, (c) the number of number names the child has spoken, (d) the number of number names the child has heard, and 
(e) the amount of time since the game began. The linear relations between numerical magnitudes and these visuospatial, kinesthetic, auditory, and temporal cues provide a broadly based, multimodal foundation for a linear representation of numerical magnitudes. Seen from another perspective, conventional board games provide a physical realization of the mental number line, hypothesized by Case and Okamoto (1996) and Case and Griffin (1990), to be the central conceptual structure underlying early numerical understanding.

\section{Board Games and Numerical Development}

The discrepancy in numerical knowledge of preschoolers from low- and middle-income backgrounds presumably is largely attributable to differing experiences with informal learning activities, including board games. A few experimental programs, such as Number Worlds (Griffin, 2000) and the Berkeley Math Readiness Project (Klein \& Starkey, 2004), have utilized number board games as part of instructional interventions designed to improve the numerical knowledge of children from low-income backgrounds. These programs have yielded substantial improvements in children's early mathematical achievement (Griffin, 2004; Klein \& Starkey, 2004). However, these and other intervention programs have included a wide range of numerical activities, not just board games but also simple arithmetic problems, monetary activities, number-related projects, number-related songs, and books and computer games that focus on numbers (Arnold, Fisher, Doctoroff, \& Dobb, 2002; Griffin, 2004; Starkey et al., 2004). This variety of activities makes it impossible to identify the causal role of any one of them. Thus, although board games have been previously utilized within educational programs for low-income children, the causal contribution of the games to improvements in the children's numerical knowledge was unknown until recently.

To determine whether playing number board game per se produces improvements in the numerical magnitude understanding of preschoolers from lowincome backgrounds, Siegler and Ramani (in press) randomly assigned children to play one of the two board games. The games differed only in the particular board that children encountered. One board included consecutively numbered, linearly arranged, equal-spaced squares. The other board was identical except for the squares varying in color but not including numbers. Each child played one of the two games with an experimenter for four sessions over a 2-week period.
Playing the numerical version of the board game led to the low-income preschool children's number line estimates becoming dramatically more linear. Before playing the number board game, the best fitting linear function accounted for an average of $15 \%$ of the variance in individual children's estimates of the numbers' magnitudes. After playing the game, the best fitting linear function accounted for an average of $61 \%$ of the variance in the individual children's estimates. This was as high as the percentage of variance in the estimates of age peers from middle-income backgrounds that was accounted for by the best fitting linear function $(60 \%)$. In contrast, playing the color board game did not affect the number line estimates of the children from lowincome backgrounds; the best fitting linear function accounted for an average of $18 \%$ of the variance in these children's estimates on both pretest and posttest. The accuracy of the children's estimates, defined as the deviation of the estimates from the correct locations, confirmed these findings. Playing the number board game produced more accurate estimates; playing the color version did not. Thus, playing the number board game for four 15- to 20-min sessions over a 2-week period produced substantial improvements in low-income children's number line estimation, which seemed attributable to their increasing use of linear representations of numerical magnitudes.

\section{The Current Study}

In the current study, we pursued five goals. The first was to replicate Siegler and Ramani's (in press) findings with a larger sample of low-income children from Head Start programs. This seemed critical because this study was the only one to date to demonstrate a causal role of number board games in improving the numerical knowledge of young children.

The second goal was to examine the generality of the effect of playing the number board game across varied numerical tasks. The only numerical task that Siegler and Ramani (in press) examined was number line estimation. In the present study, three additional measures of numerical knowledge were examined. One was the standard numerical magnitude comparison task, in which participants are asked, "Which is bigger: $\mathrm{N}$ or M?" The second and third additional tasks were counting from 1 to 10 and identifying printed numerals in that range. Playing the number board game required children to count and read printed numerals in this range; therefore, the activity was expected to lead to improvements in these skills, as well as on the two tasks believed to reflect 
representations of numerical magnitudes. Thus, we hypothesized that playing the number board game would strengthen the low-income preschoolers' number line estimation, magnitude comparison, numeral recognition, and counting skills.

A third goal of the study was to examine stability of learning over time. If playing the number board game produces a general increase in understanding of numerical magnitudes, then gains in number line estimation and numerical magnitude comparison should persist over time. If playing the game substantially increases counting and number identification skills, then gains in proficiency on these tasks should also persist. We tested these predictions by presenting the four tasks both immediately after the fourth game playing session and again 9 weeks later.

A fourth goal was to determine whether older and younger preschoolers derive similar benefits from playing the number board game. Older children might be expected to learn more because they generally learn mathematical tasks more quickly than younger children (Geary, 2006). However, younger children might learn more in this particular case because they were starting from a lower level and thus had more to learn and because the new experience with the board games would increase their total experience with numbers by a larger percentage. Yet another possibility was that these two influences would be equally strong, so that younger and older children would benefit equally. Comparing the learning of older and younger preschoolers also would help establish the age boundaries of the benefits of playing the game and provide information regarding whether playing such games produces gains over a sufficiently broad age range to be of practical use in Head Start classrooms.

The fifth goal of the study was to examine whether past experience with board games in the home environment was related to numerical knowledge at the outset of the study and to subsequent learning in the experimental situation. This goal was pursued in Experiment 2; the way in which we pursued it is described in the introduction to that experiment.

In Experiment 1, children from Head Start classrooms played either a number board game or a parallel color-based board game in four 15- to 20-min sessions over a 2-week period. The central predictions were that playing the number board game would improve children's numerical estimation, magnitude comparison, counting, and numeral identification skills; that the increases in numerical knowledge would persist over a 9-week period; and that the gains would be greater than those of children who played the color version of the game.

\section{Experiment 1}

Method

\section{Participants}

Participants were 124 preschool children (54\% female), ranging in age from 4 years 1 month to 5 years 5 months $(M=4$ years 9 months, $S D=0.44)$. They were recruited from 10 Head Start centers in an urban area. All participants met the income requirements for Head Start established by the Federal government for 2006 (e.g., for a family of three, annual income below $\$ 16,600)$. Children within each center were randomly assigned to the number board condition or to the color board condition. The number board condition included 68 children $(M=4$ years 9 months, $S D=0.46 ; 56 \%$ female; $50 \%$ African American, $43 \%$ Caucasian, and 7\% Other [Asian, Hispanic, biracial, or unknown]). The color board game condition included 56 children $(M=4$ years 9 months, $S D=$ $0.41 ; 52 \%$ female; $55 \%$ African American, $40 \%$ Caucasian, and $5 \%$ Other). In cases in which a Head Start center had an odd number of participants, the extra participant was assigned to the number board condition. An additional 12 children (4 in the number board game condition and 8 in the color board game condition) were given the pretest but did not complete the experiment for the following reasons: child withdrew from program $(N=5)$, child was absent for an extended period $(N=3)$, child had behavior problems $(N=2)$, and child refused to participate $(N=2)$. The experimenters were a female, postdoctoral research associate of Indian descent and a female, Caucasian research assistant.

\section{Materials and Procedure}

Board games. Children met individually with an experimenter in a room near their classroom for four 15- to 20-min sessions within a 2-week period and for a fifth session 9 weeks later. Each experimenter met with the same children for all the sessions in the study, approximately half in each of the two conditions. Over the first four sessions, the preschoolers played one of the two board games 20 times, with each game lasting 2-4 min. The boards were identical in almost all respects. Both were $52 \mathrm{~cm}$ long and $24 \mathrm{~cm}$ high and had "The Great Race" written across the top. Both included 10 horizontally arranged, different colored squares of equal size, with the word "Start" at the left end and the word "End" at the right end. The only difference in the boards was that the one used in the number version of the game had the numbers 1-10 listed consecutively from left to right in the squares, 
and the one used in the color version of the game did not. In addition, the number board condition had an associated spinner with a " 1 " half and a " 2 " half; the color board condition had a spinner with colors that matched the colors of the squares on the board. Children chose a rabbit or a bear token and used it to mark their progress on the board.

At the beginning of each session, the experimenter told the child that they would take turns spinning the spinner and that whoever reached the end first would win. Children in the number board condition were told that on each turn, they would move their token the number of spaces indicated on the spinner; children in the color board condition were told that they would move their token to the nearest square with the same color as the one to which the spinner pointed. The experimenter also told the child to say the number (color) that they spun and the numbers (colors) on the spaces through which they moved. Thus, children in the number board group who were on a 3 and spun a 2 would say, " $4,5^{\prime \prime}$ as they moved. Children in the color board group who spun a "blue" would say "red, blue."

If a child erred or could not name the numbers or colors, the experimenter correctly named them and then had the child repeat the names while moving the token. One common error involved children not naming the numbers in the spaces as they moved their token and instead counting the number of spaces they were to move their token forward. If such children spun a 2, they would say " 1,2 " as they moved their token similar to the way a typical board game is played, instead of saying the numbers in the spaces (e.g., "5, 6"). If children made this error, the experimenter would first remind them to name the numbers in the spaces as they moved. If children did not correct the error, the experimenter would point and name the numbers in the spaces and then have the children repeat them as she pointed to the spaces.

\section{Measures of Numerical Knowledge}

In the first, fourth, and fifth sessions, children were administered identical pretest, posttest, and followup measures of numerical knowledge. All children were presented the four tasks in the same order on the three occasions: counting, number line estimation, numerical magnitude comparison, and numeral identification. These tasks were presented before children played the board games in Session 1 and after they played them in Session 4. Session 5 consisted solely of the four tasks. No feedback was given on any of the tasks, except for general praise and encouragement.
Counting. Children were asked to count from 1 through 10. Counting was coded as correct up to the point of the first error (e.g., if a child counted " $1,2,3,4$, $5,6,7,9,10,{ }^{\prime \prime}$ her score was 7).

Number line estimation. Children were presented 18 sheets of paper, one at a time. On each sheet was a $25-\mathrm{cm}$ line, with " 0 " just below the left end and " 10 " just below the right end. A number from 1 to 9 inclusive was printed approximately $2 \mathrm{~cm}$ above the center of the line, with each number printed on 2 of the 18 sheets. All nine numbers from 1 to 9 were presented once before any number was presented twice; the order of the nine numbers was random both times. The experimenter told the child that they would be playing a game in which the child needed to mark the location of a number on a line. On each trial, after asking the child to identify the number at the top (and helping if needed), the experimenter asked, "If this is where 0 goes (pointing) and this is where 10 goes (pointing), where does N go?"

Numerical magnitude comparison. Children were presented a 20-page booklet, in which each page displayed two numbers between 1 and 9 inclusive side by side; the task was to choose the bigger number. Two example pairs with feedback were presented first, followed by 18 experimental problems (half of the 36 possible pairs). On the two examples, the experimenter pointed to each number and asked, for example, "John (Jane) had one cookie and Andy (Sarah) had six cookies. Which is more: one cookie or six cookies?" Incorrect answers were corrected and the example problems repeated until the child answered correctly. The 18 experimental problems paralleled the two example problems except that no feedback was given. Half of the children within each condition were presented a given pair in one order and half in the opposite order.

Numeral identification. The task involved 10 randomly ordered cards, each with a numeral from 1 to 10 on it. On each trial, the experimenter held up a card and asked the child to identify the numeral.

\section{Results}

We first examined multivariate effects of age, condition, and session across the four numerical tasks and then examined their effects on each task individually. On three of the tasks, a single measure of numerical knowledge was examined: number correct on the magnitude comparison task, counts without an error on the counting task, and number of numerals correctly identified on the numeral identification task. On the number line estimation task, two measures-linearity and slope-provided somewhat different types of information about performance. As shown in Figure 1a, on the number line task, the 
(a) Perfect Linearity and Slope

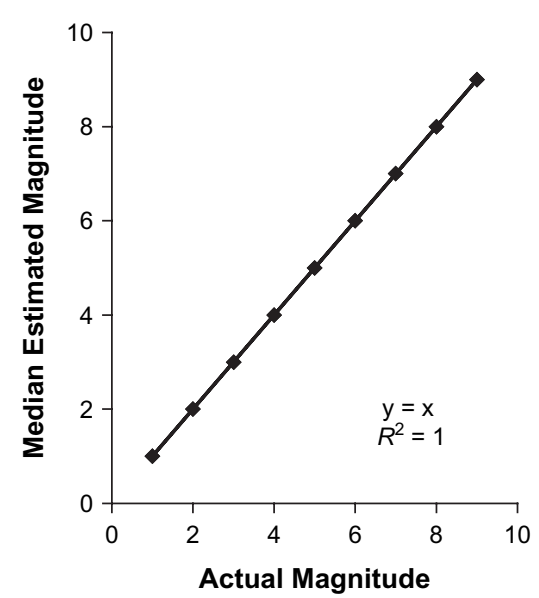

(b) Perfect Linearity, Imperfect Slope

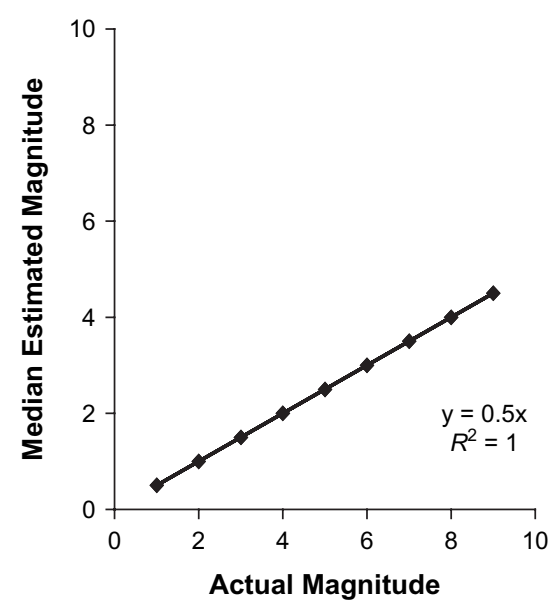

(c) Imperfect Linearity, Perfect Slope

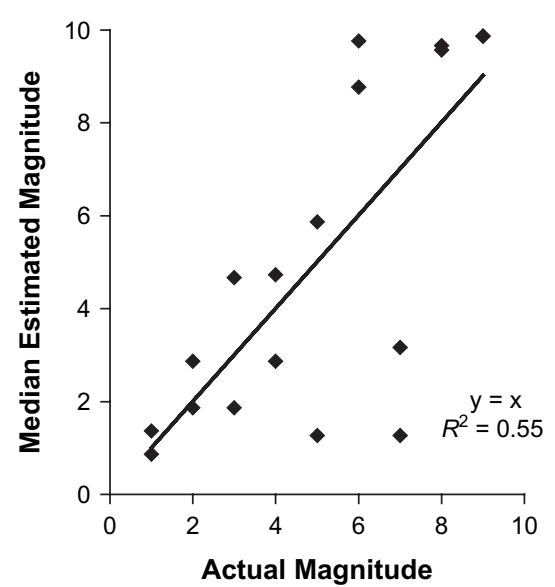

Figure 1. Relations between linearity and slopes of number line estimates: Hypothetical data.

ideal function relating actual and estimated magnitudes is perfectly linear $\left(R_{\text {lin }}^{2}=1.00\right)$ with a slope of 1.00. However, estimates can increase in a perfectly linear function with a slope far less than 1.00 (Figure 1b), and estimates can increase with a slope of 1.00 but not fit a linear function very closely (Figure 1c). For this reason, both measures were examined. To examine the age variable, a median split was used to identify a younger group of 59 children $(M=4$ years 5 months, $S D=0.21$, range $=$ 4 years 1 month to 4 years 8 months) and an older group of 65 children $(M=5$ years 1 month, $S D=$ 0.23 , range $=4$ years 9 months to 5 years 5 months). All post hoc tests were conducted using Bonferroni's $t$ statistic. In cases where the data violated sphericity (which reflected ceiling effects on some measures in the number board condition on the posttest and follow-up), the Greenhouse-Geisser correction to the degrees of freedom was used.

A 2 (age: below or above median) $\times 2$ (condition: number or color board game) $\times 3$ (session: pretest, posttest, or follow-up) repeated measures multivariate analysis of variance (MANOVA) was conducted on the five measures described aove. Effects emerged for age, $F(5,116)=11.29, p<.001, \eta_{\mathrm{p}}^{2}=.33$; condition, $F(5,116)=6.23, p<.001, \eta_{\mathrm{p}}^{2}=.21$; session, $F(10,111)=$ $11.41, p<.001, \eta_{\mathrm{p}}^{2}=.51$; and the Condition $\times$ Session interaction, $F(10,111)=6.76, p<.001, \eta_{\mathrm{p}}^{2}=.38$. To better understand the results and to examine their consistency across tasks, univariate analyses were conducted for each task.

\section{Numeral Identification}

Number of correct numeral identifications varied with age, $F(1,120)=5.66, p<.05, \eta_{\mathrm{p}}^{2}=.05$; condition,
$F(1,120)=10.20, p<.01, \eta_{\mathrm{p}}^{2}=.08$; session, $F(2,207)=$ $25.19, p<.001, \eta_{p}^{2}=.17$; and the Condition $\times$ Session interaction, $F(2,207)=9.10, p<.001, \eta_{p}^{2}=.07$. The main effect of age indicated that across conditions and sessions, older preschool children correctly identified more numerals than did their younger classmates ( 7.7 vs. 6.6 correct).

As shown in Figure 2a, the interaction between condition and session, as well as the main effects of condition and session, resulted from significant gains in numeral identification from playing the number board game and minimal gains from playing the color board game. Children who played the number board game improved from a mean of 7 to 8.2 correct identifications of the 10 numerals from pretest to posttest, $t(67)=5.42, p<.001$, Cohen's $d=0.44$, and from 7 to 8.7 correct identifications from pretest to follow-up, $t(67)=6.40, p<.001, d=0.63$. In contrast, the numeral identification skills of children who played the color board game improved minimally over sessions: 6.1 correct on the pretest, 6.3 correct on the posttest, and 6.6 correct on the follow-up. Viewed from another perspective, there was no difference between the two conditions on the pretest ( 7 vs. 6.1 correct). On the posttest, however, children who had played the number board game identified more numerals correctly than did children who had played the color board game (8.2 vs. 6.3), $t(92)=3.68, p<.001$, $d=0.69$. The same was true on the follow-up (8.7 vs. $6.6), t(95)=4.30, p<.001, d=0.80$. Thus, playing the number board game led to greater improvements in numeral identification.

We also examined the stability of individual differences in numeral identification over the pretest, posttest, and follow-up sessions. As shown in Table 1, 
(a)

Numeral Identification

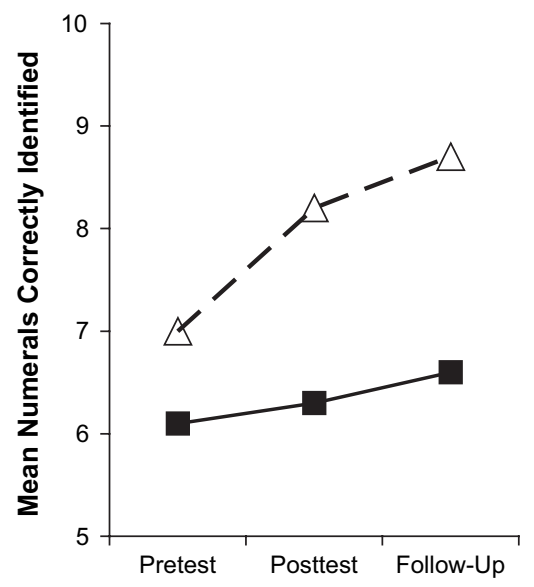

(b)

Magnitude Comparison

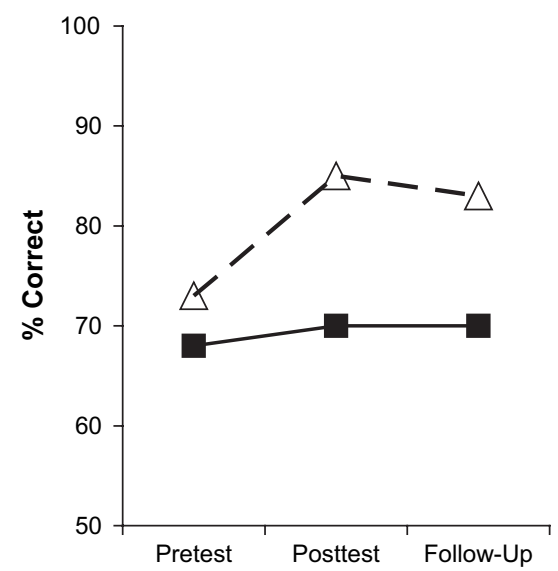

(c)

Counting

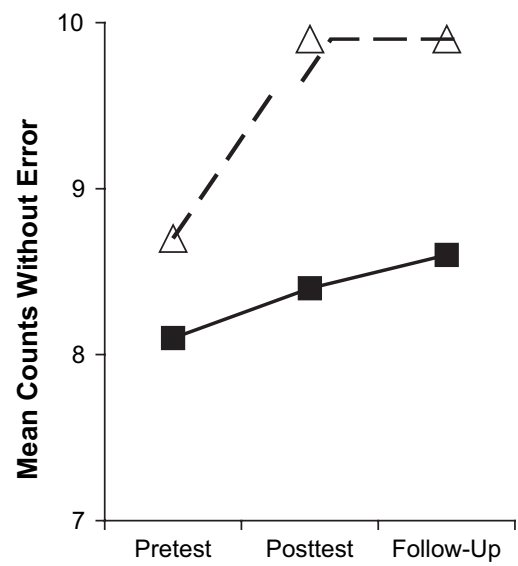

(d) Number Line Estimation:

(e) Number Line Estimation:
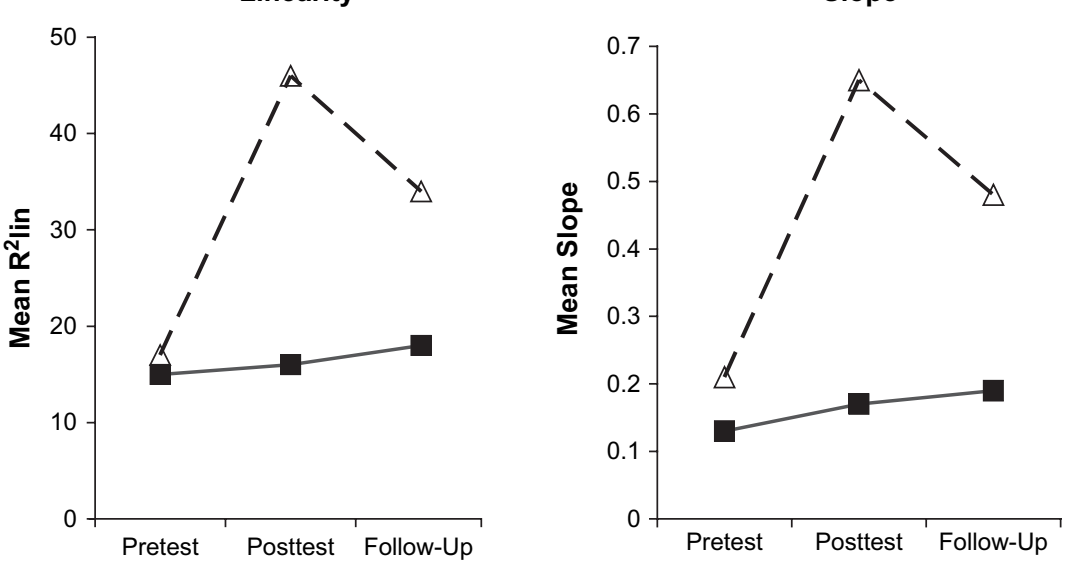

$-\Delta$ - Number Board Game

- Color Board Game

Figure 2. Individual children's performance at pretest, posttest, and follow-up on four tasks in Experiment 1.

in both conditions, the individual differences were highly stable. Thus, regardless of whether the experimental conditions led to changes in the absolute level of numeral identification skill, individual differences in the skill were highly stable from pretest to follow-up.

\section{Numerical Magnitude Comparison}

Number of correct magnitude comparisons varied with age, $F(1,120)=44.84, p<.001, \eta_{\mathrm{p}}^{2}=.27$; condition, $F(1,120)=20.17, p<.001, \eta_{\mathrm{p}}^{2}=.14$; and session, $F(2,240)=15.55, p<.001, \eta_{\mathrm{p}}^{2}=.12$, as well as with the Condition $\times$ Session interaction, $F(2,240)=$ $7.00, p<.01, \eta_{\mathrm{p}}^{2}=.06$. As on the numeral identification task, older preschoolers were more accurate than younger preschoolers across conditions and sessions (82\% vs. 67\% correct).

As shown in Figure $2 b$, the interaction between condition and session, as well as the main effects of condition and session, resulted from considerable gains in magnitude comparison accuracy after playing the number board game and negligible gains after playing the color board game. Among children who played the number board game, magnitude comparison accuracy increased from $73 \%$ on the pretest to $85 \%$ on the posttest, $t(67)=7.83, p<.001, d=0.79$, and from $73 \%$ on the pretest to $83 \%$ on the follow-up, $t(67)$ $=5.42, p<.001, d=0.57$. In contrast, there was no change over sessions in magnitude comparison accuracy for the children who played the color board game (68\% correct on the pretest, $70 \%$ correct on the posttest, and $70 \%$ correct on the follow-up). From another perspective, there was no difference between the accuracy of children in the two conditions on the pretest ( $73 \%$ vs. $68 \%$ correct). However, after playing the number board game, children correctly identified the larger number more often than peers did after playing the color board game. This was true both on 
Table 1

Correlations of Children's Performance on the Numerical Knowledge Tasks Across the Three Sessions

\begin{tabular}{lllr}
\hline & $\begin{array}{c}\text { Pretest- } \\
\text { posttest }\end{array}$ & $\begin{array}{c}\text { Pretest- } \\
\text { follow-up }\end{array}$ & $\begin{array}{c}\text { Posttest- } \\
\text { follow-up }\end{array}$ \\
\hline Color board game group & & & \\
Numeral identification & $.92^{* *}$ & $.85^{* *}$ & $.87^{* *}$ \\
Magnitude comparison & $.58^{* *}$ & $.50^{* *}$ & $.49^{* *}$ \\
Counting & $.80^{* *}$ & $.56^{* *}$ & $.67^{* *}$ \\
Number line linearity & $.84^{* *}$ & $.79^{* *}$ & $.72^{* *}$ \\
Number line slope & $.39^{*}$ & $.50^{* *}$ & $.65^{* *}$ \\
Number board game group & & & \\
Numeral identification & $.81^{* *}$ & $.71^{* *}$ & $.86^{* *}$ \\
Magnitude comparison & $.69^{* *}$ & $.57^{* *}$ & $.65^{* *}$ \\
Counting & .16 & .11 & -.03 \\
Number line linearity & $.60^{* *}$ & $.65^{* *}$ & $.65^{* *}$ \\
Number line slope & $.38^{*}$ & $.46^{* *}$ & $.63^{* *}$ \\
\hline
\end{tabular}

$* p<.01 . * * p .001$.

the posttest ( $85 \%$ vs. $70 \%$ correct), $t(95)=5.33, p<$ $.001, d=0.99$, and on the follow-up (83\% vs. $70 \%$ correct), $t(122)=4.28, p<.001, d=0.77$.

Analyses of individual differences in magnitude comparison accuracy again showed substantial stability in both conditions. As shown in Table 1, although the absolute levels of magnitude comparison proficiency increased in the number board condition and remained unchanged in the color board condition, individual differences in proficiency were stable in both conditions.

\section{Counting}

Counting skill also varied with age, $F(1,120)=8.96$, $p<.01, \eta_{\mathrm{p}}^{2}=.07$; condition, $F(1,120)=10.20, p<.01$, $\eta_{\mathrm{p}}^{2}=.08$; and session, $F(2,201)=12.35, p<.001, \eta_{\mathrm{p}}^{2}=$ .09 , and tended to vary with the Condition $\times$ Session interaction, $F(2,201)=2.81, p=.07, \eta_{\mathrm{p}}^{2}=.02$. As with numeral identification and magnitude comparison, across conditions and sessions, older preschoolers counted more accurately than younger ones (means of 9.4 vs. 8.4 numbers counted before the first error).

The tendency toward an interaction between condition and session, as well as the main effects of condition and session, again resulted from substantial gains in accuracy after playing the number board game and little or no gain after playing the color board game (Figure 2c). Children in the number board game condition improved on average from 8.7 counts before the first error on the pretest to 9.9 counts without an error on both the posttest, $t(67)=3.97$, $p<.001, d=0.65$, and the follow-up, $t(67)=4.14, p<$ $.001, d=0.69$. In contrast, there was little improve- ment in children's counting after playing the color board game: 8.1 counts without an error on the pretest, 8.4 counts without an error on the posttest, and 8.6 counts without an error on the follow-up. Viewed from a different perspective, the counting of children in the numerical and color board game conditions did not differ on the pretest ( 8.7 vs. 8.1 numbers without an error). However, children in the number board game group generated more counts without an error than did peers in the color board group on the posttest ( 9.9 vs. 8.4 correct counts), $t(61)=3.74, p<.001, d=$ 0.74 , and on the follow-up (9.9 vs. 8.6 correct counts), $t(59)=3.34, p<.01, d=0.66$.

We also compared the percentages of children in the two conditions who counted perfectly to 10. At pretest, there was no difference in the percentage of children in the two conditions who were at ceiling ( $72 \%$ vs. $63 \%$ of the children). In contrast, on the posttest, almost all children (94\%) who had played the number board game counted perfectly to $10 \mathrm{vs}$. $71 \%$ of children who had played the color board game $(N=124, p<.001$, Fisher exact test). The same difference was present at the follow-up: $97 \%$ versus $77 \%$ perfect counts in the two conditions $(N=124, p<$ .001 , Fisher exact test). Thus, after playing the number board game, almost all the children counted to 10 flawlessly.

Analyses of the stability of individual differences in counting accuracy again showed substantial stability in the color board condition, though ceiling effects led to minimal correlations in the number board condition (Table 1). The latter finding was not surprising, given the minimal variance in counting skill on both the posttest and the follow-up among children who had played the number board game (94\% and $97 \%$ of children in this condition counted perfectly on the posttest and follow-up).

\section{Number Line Estimation}

Accuracy. We obtained an overview of the accuracy of children's number line estimation by examining their percent absolute error:

$$
\left|\frac{\text { Estimate }- \text { Actual Number }}{\text { Scale of Estimates }}\right|
$$

For example, if a child marked the location of 5 on a $0-10$ number line at the position that corresponded to 9 , the percent absolute error would be $40 \%$ : $[(9-5) / 10]$.

Accuracy of number line estimation varied with age, $F(1,120)=11.50, p<.01, \eta_{\mathrm{p}}^{2}=.09$; condition, $F(1$, $120)=8.38, p<.01, \eta_{\mathrm{p}}^{2}=.07$; session, $F(2,227)=6.54$, 
$p<.01, \eta_{\mathrm{p}}^{2}=.05$; the Condition $\times$ Session interaction, $F(2,227)=11.96, p<.001, \eta_{\mathrm{p}}^{2}=.09$; and the Age $\times$ Session interaction, $F(2,227) \stackrel{p}{=} 4.95, p<.01, \eta_{\mathrm{p}}^{2}=.04$. Among children who played the number board game, percent absolute error decreased from pretest to posttest $(28 \%$ to $21 \%), t(67)=6.33, p<.001, d=0.76$, and from pretest to follow-up ( $28 \%$ to $24 \%), t(67)=3.97$, $p<.001, d=0.47$. In contrast, there was no change in the accuracy of children's estimates in the control group (mean errors $=28 \%$ at pretest, $30 \%$ at posttest, and $29 \%$ at follow-up).

Linearity. Linearity of number line estimation was the measure that most directly corresponded to the hypothetical construct of a linear representation of numerical magnitude. Among children who played the number board game, the linearity of the group median estimates for each number increased substantially from pretest to posttest and also from pretest to follow-up (Figure 3). Among children who played the color board game, no comparable changes occurred (Figure 4).

The number line estimates of individual children provided converging evidence for the group-level patterns (Figure 2d). The linearity of individual children's number line estimates varied with age, $F(1,120)$ $=17.81, p<.001, \eta_{\mathrm{p}}^{2}=.13$; condition, $F(1,120)=11.27$, $p<.01, \eta_{\mathrm{p}}^{2}=.09$; session, $F(2,240)=28.31, p<.001, \eta_{\mathrm{p}}^{2}$ $=.19$; and the Condition $\times$ Session interaction, $F(2$, $240)=23.10, p<.001, \eta_{p}^{2}=.16$. Across both conditions and sessions, the estimates of the older preschool children were more linear than the estimates of the younger preschool children (mean $R_{\text {lin }}^{2}$ for individual children $=.33$ vs. .15 ).
The interaction between condition and session, as well as the main effects of condition and session, once more resulted from substantial gains in linearity after playing the number board game and minimal gains after playing the color board game. As shown in Figure $2 \mathrm{~d}$, among children who played the number board game, the mean percent variance in individual children's estimates that was accounted for by the best fitting linear function increased from $17 \%$ on the pretest to $46 \%$ on the posttest, $t(67)=9.16, p<.001$, $d=1.00$, and from $17 \%$ on the pretest to $34 \%$ on the follow-up, $t(67)=5.52, p<.001, d=0.56$. In contrast, among children who played the color board game, linearity was virtually unchanged; the best fitting linear function accounted for a mean of $15 \%$ of the variance on the pretest, $16 \%$ on the posttest, and $18 \%$ on the follow-up. Viewed from another perspective, the linearity of estimates of children who later played the numerical and color board games did not differ on the pretest (mean $R_{\text {lin }}^{2}=.17$ vs. .15). In contrast, the estimates of children who played the number board game were considerably more linear than the estimates of those who played the color board game, both on the posttest (mean $R_{\text {lin }}^{2}=.46$ vs. .16), $t(122)=6.10$, $p<.001, d=1.08$, and on the 9-week follow-up (mean $R_{\text {lin }}^{2}=.34$ vs. .18), $t(122)=3.11, p<.01, d=.55$.

Individual differences in linearity of number line estimation, like individual differences on the other tasks, were highly stable over the pretest, posttest, and follow-up (Table 1). Thus, despite the children who played the number board game considerably increasing their linearity of number line estimates from pretest to posttest and follow-up, and children

\section{Number Board Game}
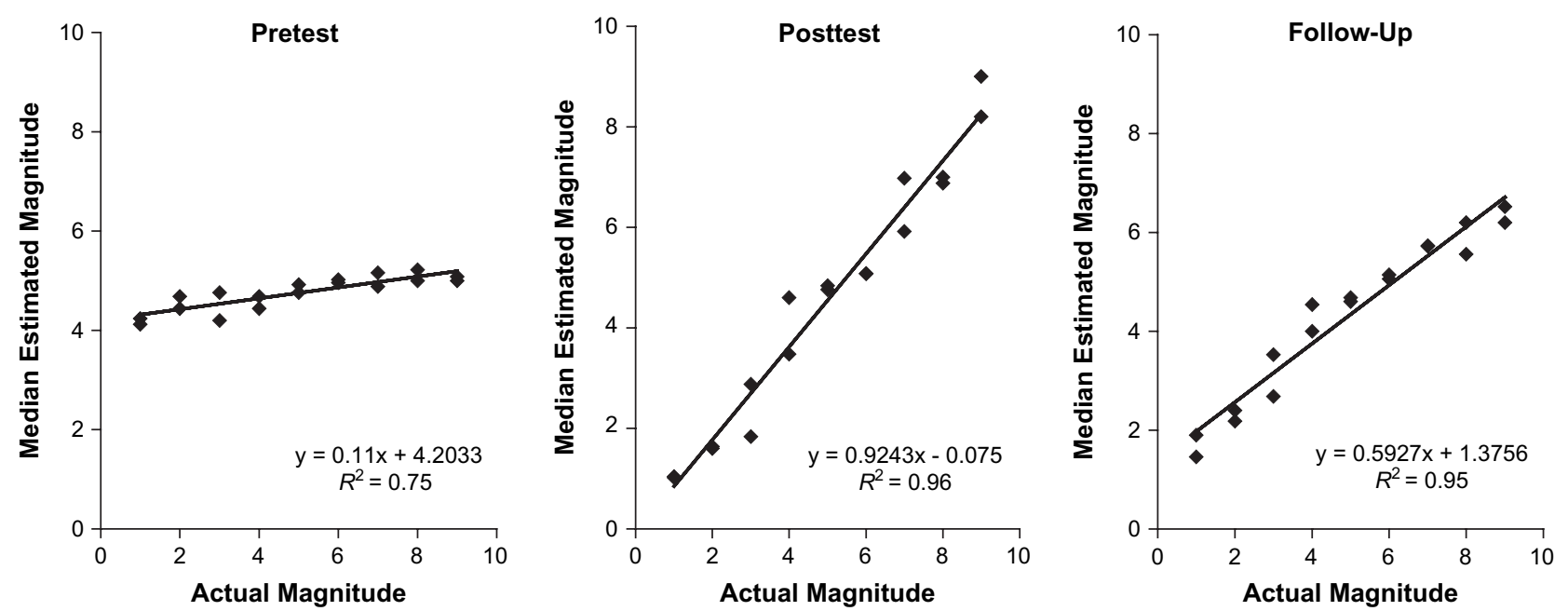

Figure 3. Best fitting linear functions for mean number line estimates on pretest, posttest, and follow-up among children who played the number board game. 

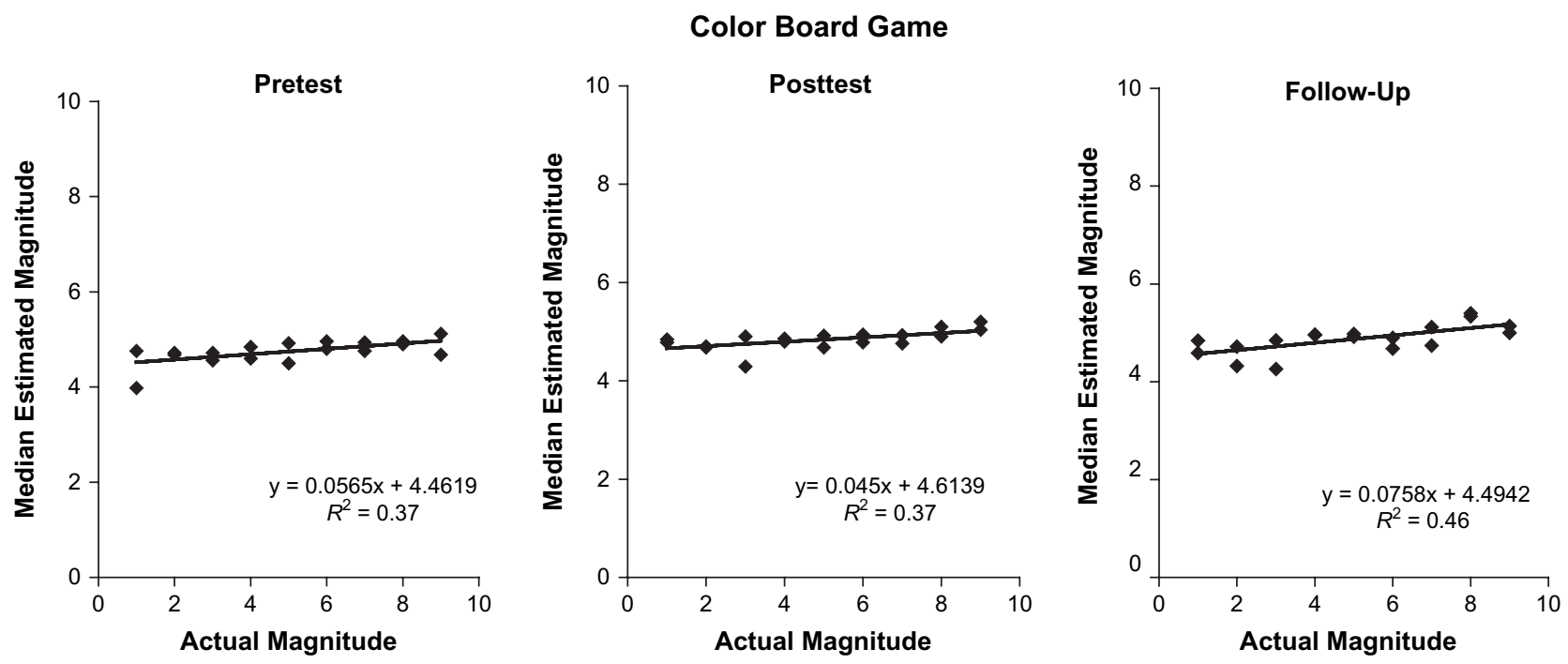

Figure 4. Best fitting linear functions for mean number line estimates on pretest, posttest, and follow-up among children who played the color board game.

who played the color board game not doing so, individual differences in linearity were highly stable in both conditions.

Slope. Among children who played the number board game, the slope of the group median estimates for each number increased substantially from pretest to posttest and also from pretest to follow-up (Figure 3). Among children who played the color board game, no comparable changes in slope were present (Figure 4).

Analyses of the slopes of individual children's estimates provided converging evidence for the group-level pattern (Figure 2e). As on all the other analyses, the slopes varied with age, $F(1,120)=22.60$, $p<.001, \eta_{\mathrm{p}}^{2}=.16$; condition, $F(1,120)=16.64, p<$ $.001, \eta_{\mathrm{p}}^{2}=.12$; session, $F(2,240)=19.99, p<.001, \eta_{\mathrm{p}}^{2}=$ .14 ; and the Condition $\times$ Session interaction, $F(2,240)$ $=12.21, p<.001, \eta_{\mathrm{p}}^{2}=.09$. The main effect of age indicated that across conditions and sessions, the estimates of the older preschool children had higher slopes than the estimates of their younger peers (mean slope $=.45$ vs. .15).

The interaction between condition and session, as well as the main effects of condition and session, once more resulted from substantial gains after playing the number board game and minimal gains after playing the color game. As shown in Figure 2e, among children who played the number board game, the slopes of number line estimates increased from pretest to posttest (mean slopes $=.21$ vs. .65),$t(67)=7.36$, $p<.001, d=0.99$, and from pretest to follow-up (mean slopes $=.21$ vs. .48$), t(67)=4.67, p<.001, d=0.59$. In contrast, there was no change in slopes among children who played the color version of the game; the mean slopes for their estimates were .13 on the pretest, .17 on the posttest, and .19 on the follow-up. Slopes in the two conditions did not differ on the pretest (mean slope $=.21$ vs. .13), but they did differ on the posttest (mean slope $=.65 \mathrm{vs} . .17), t(122)=5.77$, $p<.001, d=1.04$, and on the follow-up (mean slope $=$ .48 vs. .19$), t(122)=3.29, p<.001, d=0.59$.

Individual differences in the slopes of number line estimates, like individual differences on the other tasks, showed stability over the pretest, posttest, and follow-up (Table 1). Although not as consistent as the individual differences on the other measures, individual differences in the slopes of number line estimates were reasonably stable.

\section{Relations of Individual Differences Across Tasks}

We also examined the consistency of individual differences in numerical knowledge across the four tasks at each time of measurement. These analyses were conducted separately for children who played the number board game and those who played the color board game. One reason for conducting the separate analyses was that playing the number board game might have had a greater impact on some tasks than others, which might influence the correlations on the posttest and follow-up in that condition. Another reason was that the approach indicated the extent of replication of the findings across the two experimental conditions. Linearity of number line estimation and accuracy of magnitude comparison were both hypothesized to reflect an underlying representation of numerical magnitude (Dehaene, 1997; Gallistel \& 
Gelman, 1992), which would lead to individual differences on those tasks being substantially correlated at all three times of measurement. Based on findings from psychometric studies that numerical proficiency is a robust dimension of individual differences (Geary, 1994, 2006), we also expected positive correlations across all four tasks.

The pattern of correlations among the four measures-linearity of number line estimation, number of correct magnitude comparisons, number of numerals identified correctly, and numbers counted without an error-was consistent with these predictions at all three times of measurement. The largest correlations generally involved the two tasks hypothesized to reflect representations of numerical magnitude: number line estimation and numerical magnitude comparison. The 6 correlations involving these tasks (3 Times of Measurement $\times 2$ Experimental Conditions) ranged from $r=.42$ to $r=.55$, with a median of $r=.51$ (all $6 \mathrm{ps}<.001$ ). Counting skill generally correlated significantly with numeral identification skill but was minimally related to number line estimation and magnitude comparison performance. The 6 correlations between counting and numeral identification scores ranged from $r=.24$ to $r=.50$, with a median of $r=.40$ ( 5 of $6 p \mathrm{~s}<.05$ ); the 12 correlations between counting and the other two tasks ranged from $r=.10$ to $r=.32$, with a median of $r=.18$ ( 2 of 12 ps < .05). Finally, numeral identification correlated positively with all three other tasks, though the correlations tended to be lower than those between number line estimation and magnitude comparison. The 18 correlations involving numeral identification ranged from $r=.24$ to $r=.54$, with a median of $r=.42$ (9 of $18 p \mathrm{~s}<.001 ; 16$ of $18 \mathrm{ps}<.05$ ). This pattern suggested that three factors underlay the data: a magnitude representation factor, on which both number line estimation and magnitude comparison would load heavily; a counting skill factor; and a numeral identification factor.

To test this hypothesis, separate factor analyses were performed for children in the color board condition and for children in the number board condition. Each factor analysis included linearity of number line estimates, number of correct magnitude comparisons, number of correct numeral identifications, and number of counts before the first error for each child on the pretest, posttest, and follow-up, for a total of 12 data points per child. Separately analyzing performance in the number board and color board conditions allowed examination of whether experience playing the number board game changed the factor structure, as well as allowing replication of the factor structure across the two experimental condi- tions. The analyses used principal component analysis as the extraction method and varimax with Kaiser normalization as the rotation method. Following Stevens' (1992) recommendation for samples of this size, loadings greater than .51 were considered significant and are bolded in Table 2.

The analysis of performance of children in the color board condition yielded a clear three-factor solution (Table 2). The first component corresponded to the hypothesized numerical magnitude dimension. Performance on both the number line estimation and the magnitude comparison tasks- the two tasks hypothesized to reflect representations of numerical magnitudes-loaded heavily on this component at all three times of measurement, and neither counting nor numeral identification ever loaded substantially on it. The second component reflected numeral identification skill. The third component reflected counting skill. The three components together explained $75 \%$ of the variance in performance: the first component explained $48 \%$, the second component $18 \%$, and the third component $9 \%$.

The analysis of performance of children in the number board condition yielded a three-factor solution that was closely similar except for less clear results on the third component (Table 2). Again, the first component appeared to reflect understanding of numerical magnitudes. As in the analysis of performance in the color board condition, both number line estimation and magnitude comparison performance loaded heavily on this factor at all three times of measurement. Also as in the analysis of performance in the color board condition, the second factor seemed to reflect skill at numeral identification. Performance on this task at all three times of measurement loaded heavily on this component, though counting performance on the pretest also loaded somewhat on it. The third component was more difficult to interpret. As with the analysis of data from the color board condition, counting skill on the follow-up loaded heavily on it. However, counting performance on the pretest did not load on it, and counting performance on the posttest loaded negatively on it. It seems likely that the minimal variance in counting performance at two of the three times of measurement among children who played the number board game contributed to this anomalous pattern: Recall that $94 \%$ of children in this condition counted perfectly on the posttest and $97 \%$ counted perfectly on the follow-up. The three components together explained $64 \%$ of the variance in performance: the first component explained $43 \%$, the second component $13 \%$, and the third component $9 \%$. Thus, the pattern of individual differences among children who played the number board game largely 
Table 2

Factor Loadings for the Numerical Knowledge Measures Across the Three Sessions

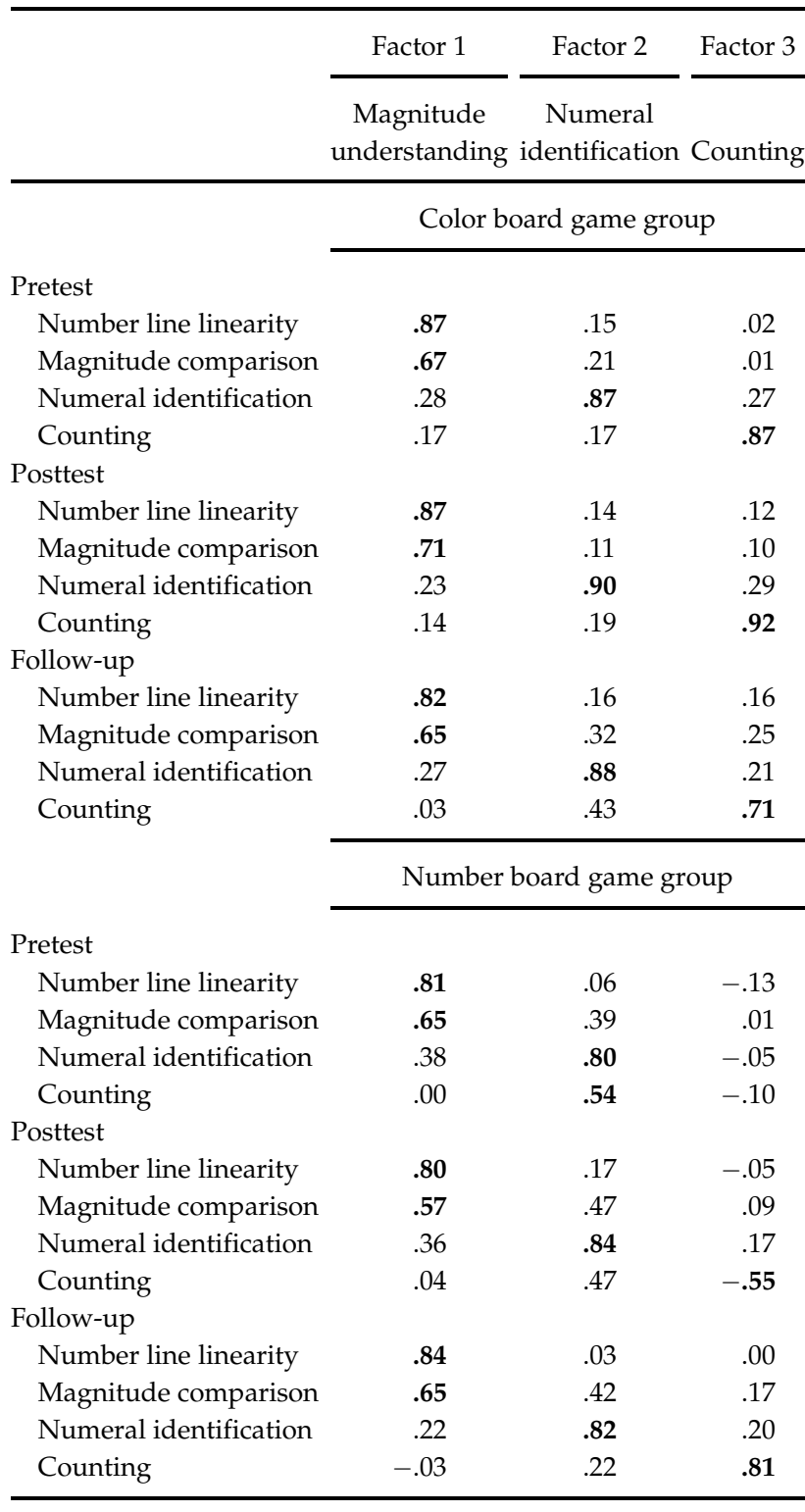

Note. Following Stevens' (1992) recommendation for samples of this size, loadings greater than .51 are considered significant and are boldface.

replicated that among children who played the color board game.

\section{Discussion}

After playing a linearly arranged number board game for four 15- to 20-min sessions, children from Head Start programs showed considerable improvement in numerical magnitude comparison, number line estimation, numeral identification, and counting.
These findings both replicate and extend the findings of Siegler and Ramani (in press). Consistent with the earlier findings, the accuracy, linearity, and slope of children's number line estimates improved after playing the number board game. In addition, the present findings went beyond the previous ones in demonstrating that these improvements were general over both tasks and time. Playing the number board game resulted in substantial improvements on all four tasks that were examined. Moreover, even though the children had not seen the number board game for 2 months, the learning that was apparent immediately after playing the number board game remained strongly apparent 9 weeks later. The lack of improvement among children who played the color board game demonstrated that these gains after playing the number board game were not attributable to maturation, repeated testing, experiences in the Head Start classrooms, interactions with the adult experimenter, enjoyment of playing a board game, controlled movements of tokens along the game board, or a host of other imaginable factors.

The experiment also examined developmental differences in the preschoolers' knowledge and learning. The older preschool children exhibited greater initial knowledge than their younger peers on all four numerical tasks. However, the differences on the pretest neither grew nor shrank on the posttest and follow-up; age and session never interacted. Thus, the older preschoolers had greater initial numerical knowledge, but the learning of older and younger preschoolers was comparable. This finding suggests that throughout the range of ages and numerical knowledge represented among children in the present experiment, playing the number board game increases numerical knowledge by comparable amounts.

\section{Experiment 2}

The basic argument of this article is that playing linear number board games contributes to both individual and group differences in numerical knowledge at the time that children enter school. The results of Experiment 1 provided one type of support for this argument: In a laboratory setting, playing number board games improved preschoolers' numerical knowledge, and the gains were broad and stable over time.

The purpose of Experiment 2 was to provide a different type of evidence relevant to the argumentevidence regarding activities in the home environment. It seems likely that both individual and socioeconomic differences in the numerical knowledge that children bring to school arise in large part 
from differences in informal numerical experiences in the preschool years. To test this hypothesis, we obtained data about home experiences with board games, card games, and video games of preschoolers from low- and middle-income families. The main hypotheses were that amount of experience playing board games would correlate positively with numerical knowledge and that children from middleincome backgrounds would have greater experience with board games than would children from lowincome backgrounds.

A few prior studies have examined preschoolers' informal numerical experiences. Mothers from middle-class and working-class families report playing similar amounts of number-relevant games, such as dominoes, in their homes (Saxe et al., 1987). Observational studies indicate that in the preschool context, children from high-, middle-, and low-income backgrounds engage in similar amounts of math-related play, such as counting toys, comparing the sizes of objects, and arranging objects into patterns (Ginsburg, Inoue, \& Seo, 1999; Seo \& Ginsburg, 2004). However, no published studies appear to have addressed children's exposure to specific types of games at home or the relation of such exposure to their numerical knowledge. Given the Experiment 1 findings that playing a number board game in the lab increased preschoolers' numerical knowledge, it seemed useful to determine whether children's board game experience at home is related to their numerical knowledge and whether the board game experience of children from low- and middleincome backgrounds differs in ways that parallel the discrepancy in their numerical knowledge.

Informal activities other than board games, in particular card games, also may influence early numerical knowledge. For example, in the card game War, the player with the higher card wins the other player's card. For cards from 2 to 10, children can determine the winner by identifying the numerals on the pair of cards and comparing their magnitudes. Playing card games such as War thus might improve numeral identification and magnitude comparison skills.

It seemed possible, but less likely, that playing video games would promote preschoolers' numerical knowledge. Some video games are designed to teach young children counting, arithmetic, and other number skills, but they are a small percentage of all such games and are not among the most popular. The relation between preschoolers' numerical knowledge and the number of video games in their homes is currently unknown, as is the relation between the number of video games in the homes of low- and middle-income preschoolers. Therefore, in Experi- ment 2, we obtained self-report data regarding home experiences playing board games, card games, and video games from the preschoolers from low-income backgrounds who participated in Experiment 1 and from a group of age peers from middle-income backgrounds.

\section{Method}

\section{Participants}

Participants were 145 preschool children, 51\% of whom were female, ranging in age from 4 years 1 month to 5 years 5 months ( $M=4$ years 9 months, $S D=0.43)$. Thirty of the children were recruited from a predominately middle-class, university-run preschool $(M=4$ years 9 months, $S D=0.36 ; 43 \%$ female; $87 \%$ Caucasian and $13 \%$ Asian). The other 115 participants were children from Experiment 1 who attended Head Start centers $(M=4$ years 9 months, $S D=0.44 ; 53 \%$ female; $52 \%$ African American, $41 \%$ Caucasian, and $7 \%$ Other). The self-reports of these children were obtained in a session after the 9-week follow-up. Data for Experiment 2 were not collected from 9 children from the original low-income sample due to their not being present when the data were collected.

\section{Procedure}

Children met individually with an experimenter in a room near their classroom where they were administered a set of questions to assess their game playing experience outside of preschool. The experimenter asked whether the children ever played board games, card games, and video games at their homes or at other family members' or friends' homes. If children responded "yes" to any of these questions, they were asked whether they played that type of game "all the time, sometimes, or hardly ever" and also were asked to name each board game, card game, and video game they had played outside of preschool.

\section{Results and Discussion}

\section{Game Play Outside of School}

We first examined whether there were differences between children from low- and middle-income backgrounds in whether they ever had played each type of game outside of preschool. As expected, a higher percentage of children from middle-income backgrounds reported having played at least one board 
game at home or at the homes of friends or relatives. To be specific, $80 \%$ of the middle-class children reported playing one or more board games outside of preschool, whereas $47 \%$ of the Head Start children $\operatorname{did}(N=145, p<.01$, Fisher exact test). Similarly, a higher percentage of children from middle-income families reported having played one or more card games at their home or at friends' or relatives' homes ( $87 \%$ vs. $61 \%, N=145, p<.01$, Fisher exact test).

A difference in the opposite direction was found for video games; $66 \%$ of the children who attended Head Start centers reported playing video games at home or at a friend's or relative's house, but only $30 \%$ of the children from middle-income backgrounds did $(N=144, p<.01$, Fisher exact test; this question was inadvertently not posed to 1 child). This last finding argued against the possibility that the first two differences reflected middle-income children being more willing to report playing games or better remembering their game playing experience. Why would such differences in reporting standards or memory be present for board games and card games but differences in the opposite direction be present for video games?

We then compared the number of board games, cards games, and video games that children from the middle- and low-income backgrounds named as ones that they had played at their or other people's homes. Consistent with the previous findings, children from middle-income backgrounds named a greater number of specific board games than the Head Start children as ones they had played outside of preschool (Ms $=1.90$ vs. 0.96 board games), $t(143)=4.02, p<$ $.001, d=0.82$. Children from middle-income backgrounds also listed a greater number of card games as ones they had played outside of school ( $M s=1.20 \mathrm{vs}$. 0.82 card games), $t(143)=2.21, p<.05, d=0.45$. In contrast, children who attended Head Start centers named a greater number of video games as ones they had played at home ( $M s=1.3$ vs. 0.4 video games), $t(74)=4.01, p<.001, d=0.95$.

Table 3 lists the percentage of children from lowand middle-income backgrounds who reported playing the most common games in each of the three categories. Children in the two groups most often reported playing the same specific board games and card games outside of school. The situation differed somewhat for the video games because children named a far greater variety of them (65) than board games or card games. This necessitated dividing the video games into three main genres: action/adventure, educational, and sports. As can be seen in Table 3, the absolute percentages for all three genres of video games were higher for children from low- income backgrounds, though the difference was smaller for educational games than for the other two types of games.

\section{Game Playing Experience and Number Knowledge}

To determine whether low-income preschoolers' number knowledge was related to their game playing activities outside of school, we correlated their pretest performance in Experiment 1 with their experience playing different types of games in the home environment. As shown in Table 4, the number of board games that the Head Start children named was positively correlated with measures of numerical knowledge on all four tasks. In contrast, the numbers of card games and video games that children named were only correlated with one task apiece.

To further examine the relations between children's number knowledge and their game playing experience, we divided the Head Start children into three groups, based on the number of contexts in which they indicated that they played board games outside of school. The groups were (a) children who did not report playing any board games, (b) children who reported playing board games at one location (own home or others' homes), and (c) children who reported playing board games at multiple locations (own and others' homes).

A MANOVA comparing the three groups' performance on the five measures of numerical knowledge examined in Experiment 1 indicated that numerical knowledge varied with the number of contexts in which children played board games, $F(10,216)=2.37$, $p<.05, \eta_{\mathrm{p}}^{2}=.10$. Children who played board games in more contexts had greater numerical knowledge than the other children. Univariate analyses indicated that children who played board games in a greater number of informal contexts more accurately identified numerals, $F(2,112)=3.02, p=.05, \eta_{p}^{2}=.05$; more accurately compared numerical magnitudes, $F(2,112)$ $=3.04, p=.05, \eta_{\mathrm{p}}^{2}=.05$; and generated number line estimates that were more linear, $F(2,112)=9.16, p<$ $.001, \eta_{\mathrm{p}}^{2}=.14$, and that tended to have higher slopes, $F(2,112)=2.89, p<.10, \eta_{\mathrm{p}}^{2}=.05$. Parallel MANOVAs did not reveal any relation between the variety of contexts in which children played card games and video games and their numerical knowledge.

One number board game, Chutes and Ladders, was named by a fairly high percentage of preschoolers (17\%). Because we hypothesized that linear number board games like this one are especially important for gaining numerical knowledge, we performed biserial correlations on whether children who reported playing this game had greater 
Table 3

Percentage of Children Who Reported Playing Specific Board Games, Card Games, and Types of Video Games

\begin{tabular}{|c|c|c|c|}
\hline \multirow[b]{2}{*}{ Game } & \multirow[b]{2}{*}{ Description } & \multicolumn{2}{|c|}{ Percent children who named game } \\
\hline & & Head Start & Middle income \\
\hline \multicolumn{4}{|l|}{ Board games } \\
\hline Candyland & $\begin{array}{l}\text { Players move tokens along winding path with colored spaces. } \\
\text { First to end wins. }\end{array}$ & 29 & 63 \\
\hline Chutes and Ladders & $\begin{array}{l}\text { Players move tokens along linearly ordered squares numbered } \\
\text { from } 1 \text { to } 100 \text {. First to reach Square } 100 \text { wins. }\end{array}$ & 17 & 37 \\
\hline Checkers & $\begin{array}{l}\text { Players move tokens diagonally on spaces of a checkerboard to } \\
\text { capture opponent's pieces by jumping over them. First to } \\
\text { eliminate opponent's pieces wins. }\end{array}$ & 9 & 10 \\
\hline \multicolumn{4}{|l|}{ Card games } \\
\hline Go Fish & $\begin{array}{l}\text { Players ask other players for card to form pairs with their } \\
\text { own cards. First to make pairs with all their cards wins. }\end{array}$ & 30 & 37 \\
\hline Uno & $\begin{array}{l}\text { Players place a card that matches the suit or rank of the } \\
\text { current top card on top of the pile. First to use all cards wins. }\end{array}$ & 9 & 33 \\
\hline Old Maid & $\begin{array}{l}\text { Players choose cards from opponents and make pairs with } \\
\text { own cards. Player with "Old Maid" card at end of game loses. }\end{array}$ & 11 & 20 \\
\hline Memory & $\begin{array}{l}\text { Cards are placed face down. Players choose cards to } \\
\text { find matches. Player with the most matches wins. }\end{array}$ & 8 & 10 \\
\hline \multicolumn{4}{|l|}{ Video games } \\
\hline Action/adventure & $\begin{array}{l}\text { Games with exploration and interaction with game characters } \\
\text { (e.g., Super Mario Brothers, Donkey Kong, Sonic). }\end{array}$ & 38 & 13 \\
\hline Education & $\begin{array}{l}\text { Games marketed for educational value (e.g., Dora the Explorer } \\
\text { video game focuses on solving puzzles and problems). }\end{array}$ & 22 & 17 \\
\hline Sports & Sports games (e.g., football, baseball, car racing). & 17 & 3 \\
\hline
\end{tabular}

numerical knowledge than those who did not report playing it. (The correlation was computed only for the children from low-income backgrounds because they were the only ones for whom the measures of numerical knowledge were available.) Despite the crude dichotomous measure of experience with this number board game, whether children reported having played Chutes and Ladders was correlated with four of the five measures of numerical knowledge: accuracy of numeral identification, $r_{b}(113)=.24, p<.01$; errorless counts, $r_{b}(113)=.19, p<.05$; linearity of number line estimates, $r_{b}(113)=.20, p<.05$; and slope of number line estimates, $r_{b}(113)=.26, p<.01$.

\section{General Discussion}

This study tested the hypotheses that playing linear number board games is a source of social class and individual differences in young children's numerical knowledge and also a potential means for reducing these differences. Results of the study supported both hypotheses. Children from low-income backgrounds reported only half as much experience playing board games as age peers from middle-income backgrounds; indeed, the majority of children in the lowincome sample reported never having played a board game at home or at the homes of friends or relatives. The amount of board game experience that they

Table 4

Correlations Between the Number of Board Games, Card Games, and Video Games That Head Start Children Reported Having Played Outside of Preschool and Their Performance on the Number Knowledge Tasks on the Pretest of Experiment 1

\begin{tabular}{lcccc}
\hline Number knowledge tasks & Numeral identification & Magnitude comparison & Counting & Number line linearity \\
\hline Board games & $.25^{* *}$ & $.26^{* *}$ & $.20^{*}$ & $.38^{* * *}$ \\
Card games & .13 & $.28^{* *}$ & .11 & .18 \\
Video games & .07 & .02 & .00 & $.21^{*}$ \\
\hline
\end{tabular}

${ }^{*} p<.05 . * * p<.01 . * * * p<.001$. 
reported was positively correlated with their numerical knowledge. Most convincing, playing a linear number board game with children from low-income backgrounds for four 15- to 20-min sessions led to large, broad-based, stable gains in numerical knowledge. In this concluding section, we summarize the results of the study in terms of its five main goals and then consider theoretical and applied issues raised by the findings.

\section{The Impact of Playing Number Board Games}

The present study was designed to pursue five goals: to replicate a previous finding that playing linearly arranged number board games improved low-income preschoolers' number line estimation, to determine the effects of playing such games on a broader range of numerical tasks, to establish whether the increases in numerical knowledge are stable over time, to examine developmental differences in learning, and to test whether informal experience playing such games in the home environment is positively related to numerical knowledge.

With regard to the first goal, the results of Experiment 1 replicated Siegler and Ramani's (in press) finding that playing a linear number board game improves the accuracy, linearity, and slope of number line estimates. The results of the present study also lent support to Siegler and Ramani's theoretical interpretation - that the improvement in number line estimation was indicative of a more general increase in understanding of numerical magnitude. Consistent with this interpretation, children who played the number board game improved on the numerical magnitude comparison task as well as on the number line estimation task. The individual difference data within each experimental condition also supported the theoretical interpretation. Results of the factor analysis indicated that individual differences on these two tasks in all three sessions loaded on the same factor and that performance on the other tasks never loaded on that factor. The findings also were consistent with those of Malofeeva, Day, Saco, Young, and Ciancio (2004), who found a similar distinction between knowledge of magnitudes and specific numerical skills.

With regard to the second goal, the present findings extended those of Siegler and Ramani (in press) by demonstrating that playing the number board game enhanced counting and numeral identification as well as understanding of numerical magnitudes. Children's counting improved to the point where $94 \%$ of children were at ceiling on the posttest and $97 \%$ on the follow-up. Counting, numeral identification, and understanding of magnitudes all seem crucial for acquiring more advanced numerical competence, for example, proficiency at arithmetic.

Because numerical skills tend to be positively correlated, it might be argued that teaching other numerical skills, such as counting and numeral identification, would have had the same beneficial effects as playing the number board game. However, results of a previous study that involved giving children at Head Start centers instruction, practice, and feedback with counting and numeral identification suggest otherwise. Malofeeva et al. (2004) found that this type of intervention led to improvements in counting and numeral identification but not to improvement on tasks that assessed understanding of numerical magnitudes, including numerical magnitude comparison. This is not to deny the value of practice with counting and numeral identification but rather to note that the value of playing number board games extends to a broader range of numerical skills. Given that substantial positive correlations between understanding of numerical magnitudes and overall math achievement test scores are present at least through fourth grade (Booth \& Siegler, 2006), gains in this type of understanding may be an especially important contribution of playing number board games.

With regard to the third goal, the benefits of playing the number board game remained apparent 9 weeks after the experience on all four tasks. The stability of the changes was consistent with the interpretation that playing the number board game helps create a representation akin to the numerical central conceptual structure hypothesized by Case and Okamoto (1996) to underlie a broad range of numerical capabilities.

The fourth goal of the study was to examine developmental differences in existing knowledge and learning. On all four tasks, older children exhibited greater knowledge of numbers than younger children throughout the experiment. However, the absence of interactions involving the age variable indicated that older and younger children learned a similar amount from playing the number game. This finding indicates that both older and younger children within Head Start centers derive substantial benefits from playing the game.

The fifth goal of the study was to determine whether informal game playing experience was related to numerical knowledge. As hypothesized, children who had more experience playing board games at their own and other people's homes also exhibited greater numerical knowledge. The relation was even present when only experience playing the 
single number board game Chutes and Ladders was considered. Reported experience playing card games and video games was not closely related to numerical knowledge, thus indicating that the correlations with board game experience were not due to numerically advanced children having better memory for their game playing experience or being more willing to report it. In addition, children from middle-income backgrounds reported playing more board games, though fewer video games, than age peers from lowincome backgrounds.

All these findings converged on two conclusions. First, differing experience with board games is one source of the gap between the numerical knowledge of children from more and less affluent backgrounds when they enter school. Second, this gap can be reduced by providing children from low-income backgrounds experience playing number board games.

\section{Issues Raised by the Present Findings}

\section{Future Learning}

The present findings demonstrated that the benefits of playing number board games include enhanced understanding of numerical magnitudes, improved counting, and improved numeral identification. These gains are not only important in themselves but also seem likely to increase children's ability to acquire further numerical information.

Consider how each of the skills is likely to facilitate learning of arithmetic that is the major focus of mathematics instruction in elementary school. Counting skill is necessary for executing many arithmetic strategies, such as adding by counting from 1 (the sum strategy), adding by counting-on from the larger addend (the min strategy), subtracting by countingup from the subtrahend, and subtracting by counting down from the minuend. Consistent with this interpretation, individual differences in first graders' counting skill have been found to correlate positively with differences in their arithmetic proficiency (Geary, BowThomas, \& Yoa, 1992). Also consistent with the interpretation, accurate execution of counting-based arithmetic strategies is predictive of accurate retrieval of answers to arithmetic problems (Siegler, 1988). Automaticity in numeral identification reduces working memory load, which is also correlated with skill in solving arithmetic problems (Geary, 2006).

A similar relation is present between numerical magnitude representations and arithmetic proficiency. Linearity of number line estimation correlates substantially with arithmetic proficiency (Booth, 2005). It also correlates substantially with kindergartners' through fourth graders' math achievement test scores (Booth \& Siegler, 2006; Siegler \& Booth, 2004); to a large degree, such tests are assessments of arithmetic skill. Moreover, providing first graders with accurate representations of the addends' and sums' magnitudes helps them learn answers to novel addition problems (Booth, 2005).

A likely reason for the relation between arithmetic proficiency and linearity of numerical magnitude representations is that presentation of arithmetic problems activates not only a verbal representation of the correct answer but also an approximate magnitude representation (Hanich, Jordan, Kaplan, \& Dick, 2001). This can be seen in the finding from verification tasks that people reject false answers that are distant in magnitude from the correct answer more rapidly than false answers that are closer to it (they more rapidly reject $3+8=17$ than $3+8=13$ ) (Ashcraft, 1992; Ashcraft, Fierman, \& Bartolotta, 1984). This analysis suggests that playing number board games should help children later learn arithmetic, not only because it improves counting and numeral recognition but also because it enhances understanding of numerical magnitudes.

\section{Formation of Mental Representations}

The present findings raise many questions about how interactions with physical materials help children form more advanced mental representations. Some of these questions can be addressed by determining which features of materials and of children's interactions with them influence learning.

In the present context, one feature that may be important to the formation of more advanced numerical magnitude representations is the linearity of the board. Preschoolers may implicitly take the approach, "The further toward the goal the token is, the bigger the number in that square." If so, circular board games would be less effective than linear ones. Such a finding would suggest more generally that physical objects that translate simply into mental representations of fundamental concepts (the linear ruler representation of numerical magnitude in this case) may play an important role in cognitive development.

Another feature of numerical board games that may be important is the kinesthetic cues produced by physically moving the tokens. If so, having the experimenter move the tokens should produce less learning than having the child move them. The embodied cognition approach (Thelen, 1996; Wilson, 2002) implies that the child's physical movements should contribute to formation of more advanced conceptual representations in this and other contexts. 
A third feature that may be crucial for forming more advanced representations of numerical magnitude is counting-on from the current number, which usually will be a number greater than 1 . Identifying the value of the current number and counting-up from there has been hypothesized to be crucial for understanding numerical magnitudes and arithmetic (Secada, Fuson, \& Hall, 1983).

Yet another question relevant to the issue of how conceptual representations are formed is whether the variety of redundant cues that support formation of linear representations of numerical magnitudes may be crucial, as opposed to any particular cue being essential. The above-cited cues, as well as others such as the total distance traveled and the time for which the game has been played, may be important not in and of themselves but rather because of their mutually reinforcing properties. This interpretation is similar to the "gang effect" in parallel distributed processing (PDP) models of speech perception, reading, and other skills (e.g., McClelland \& Elman, 1986). Within this interpretation, the best predictor of learning should be the number of redundant cues rather than which ones are present. Creating versions of The Great Race that vary in the number of redundant cues would allow evaluation of this hypothesis. More generally, all these experiments should help determine the mechanisms through which number board games help young children construct more advanced representations of numerical magnitude.

\section{The Sociocultural Context}

The present study reflects the view that the environment in which cognition develops is a major determinant of social class, developmental, and individual differences in cognition. We also believe that understanding cognitive development requires detailed analysis of the specific, relevant activities in which children engage in informal settings. Although no one denies the importance of the everyday environment, the way in which it exerts its influence on cognitive development is rarely the focus of research. The number of cognitive developmental studies that center on this topic is dwarfed by the number that examine the ages at which various competencies emerge and the aspects of situations that influence performance.

The few studies that have focused on environmental influences on numerical development (e.g., Ginsburg et al., 1999; Mix, 2002; Saxe et al., 1987) reveal the promise of doing so. Even everyday routines that do not explicitly involve numbers, such as passing out napkins during dinner, promote concepts that are foundational for understanding numbers, such as one-to-one correspondence (Mix, 2002).

The present study combined an analysis of the development of children's mental representations of numerical magnitudes with an analysis of the properties of games that might promote relatively advanced representations. These analyses suggested that linear number board games such as Chutes and Ladders, which provide a clear physical basis for linear mental representations of numerical magnitude, would be particularly likely to promote learning about such magnitudes. The plausibility of the hypothesis increased with the finding that amount of board game play in general, and experience with Chutes and Ladders in particular, correlated positively with performance on all four numerical tasks. The finding that middle-income children have more experience playing board games in general, and Chutes and Ladders in particular, increased the plausibility of the related hypothesis that variations in experience with such games are one source of differences between the numerical knowledge of children from low- and middle-income backgrounds.

Not all games that could plausibly promote numerical knowledge actually do so. Some card games and video games include numerical content, but in the present study at least, playing such games was largely unrelated to numerical knowledge. This is consistent with the previous finding that when low-income kindergarteners were given educational video games to play in their classrooms and at home, their mathematics abilities did not show any improvement relative to peers who were not given the games (Din \& Calao, 2001). One likely reason is that even though computer and video games are often marketed as promoting mathematics and problem-solving skills, many of these games only explore numerical concepts at very rudimentary levels (Sarama \& Clements, 2002). Computerbased games, especially if they are combined with relevant classroom activities and materials, can offer children ways to develop skills and draw connections among concepts (Sarama, 2004; Sarama \& Clements, 2002). However, this may not be true of the video games that young children typically play. Incorporation of cognitive developmental data into the design process may lead to construction of new games that are more effective than the ones that are commonly played now.

\section{Practical Implications and Issues}

Number board games such as The Great Race are promising candidates for broad adoption in Head Start centers, child-care centers, and individual homes. They cost little or nothing; anyone with 
a pencil and large piece of paper can create a board, and creating a spinner with a " 1 " half and a " 2 " half is also easy. No special skills appear to be required for parents, child-care, and Head Start personnel to play the games with children. An additional advantage is that children enjoy playing such games, based both on current observations and on the games' enduring popularity in diverse societies.

There is also no reason to believe that the present version of The Great Race cannot be improved. Many features of the intervention were based on hunches and guesses rather than empirical research. One such feature is amount of game playing experience. The decision to have children play the game four times was completely arbitrary. Varying the number of sessions would indicate whether children would derive greater benefits from playing the game for more sessions or, conversely, whether the benefits quickly reach asymptotic levels.

Another class of issues involves scaling-up the current intervention from an experimental program to one implemented by parents and childcare and Head Start personnel. Although the lack of effects of the color board control condition indicated that the benefits of playing the number board game were not due to a Hawthorne effect, having highly motivated project personnel playing the game with children might have interacted with the nature of the game. Such effects have been found in other contexts, such as programs involving reading to children from lowincome backgrounds (Whitehurst et al., 1994). A related issue is whether the game produces comparable learning if played in small groups. Addressing these issues should increase theoretical understanding of numerical development, as well as helping children from low-income backgrounds acquire more advanced numerical representations.

\section{References}

Alexander, K. L., \& Entwisle, D. R. (1988). Achievement in the first 2 years of school: Patterns and processes. Monographs of the Society for Research in Child Development, 53(2, Serial No. 157).

Arnold, D. H., Fisher, P. H., Doctoroff, G. L., \& Dobb, J. (2002). Accelerating math development in Head Start classrooms. Journal of Educational Psychology, 92, 762-770.

Ashcraft, M. H. (1992). Cognitive arithmetic: A review of data and theory. Cognition, 44, 75-106.

Ashcraft, M. H., Fierman, B. A., \& Bartolotta, R. (1984). The production and verification tasks in mental addition: An empirical comparison. Developmental Review, 4, $157-170$.

Banks, W. P., \& Coleman, M. J. (1981). Two subjective scales of numbers. Perception and Psychophysics, 29, 95-105.
Booth, J. L. (2005). The importance of an accurate understanding of numerical magnitudes. Unpublished doctoral dissertation, Carnegie Mellon University, Pittsburgh, Pennsylvania.

Booth, J. L., \& Siegler, R. S. (2006). Developmental and individual differences in pure numerical estimation. Developmental Psychology, 41, 189-201.

Bransford, J. B., Brown, A. L., \& Cocking, R. R. (Eds.). (1999). How people learn: Brain, mind, experience, and school. Washington, DC: National Academy Press.

Case, R., \& Griffin, S. (1990). Child cognitive development: The role of central conceptual structures in the development of scientific and social thought. In C. A. Hauert (Ed.), Developmental psychology: Cognitive, perceptuomotor, and neuropsychological perspectives (pp. 193-230). Amsterdam: Elsevier Science.

Case, R., \& Okamoto, Y. (1996). The role of central conceptual structures in the development of children's thought. Monographs of the Society for Research in Child Development, 61(1-2, Serial No. 265).

Dehaene, S. (1997). The number sense: How the mind creates mathematics. New York: Oxford University Press.

Din, F. S., \& Calao, J. (2001). The effects of playing educational video games on kindergarten achievement. Child Study Journal, 31, 95-102.

Duncan, G. J., Dowsett, C. J., Claessens, A., Magnuson, K., Huston, A. C., Klebanov, P, et al. (2007). School readiness and later achievement. Developmental Psychology, 43, $1428-1446$.

Gallistel, C. R., \& Gelman, R. (1992). Preverbal and verbal counting and computation. Cognition, 44, 43-74.

Geary, D. C. (1994). Children's mathematics development: Research and practical applications. Washington, DC: American Psychological Association.

Geary, D. C. (2006). Development of mathematical understanding. In W. Damon \& R. M. Lerner (Series Eds.) \& D. Kuhn \& R. S. Siegler (Vol. Eds.), Handbook of child psychology: Vol 2. Cognition, perception, and language (6th ed., pp. 777-810). New York: Wiley.

Geary, D. C., Bow-Thomas, C. C., \& Yoa, Y. (1992). Counting knowledge and skill in cognitive addition: A comparison of normal and mathematically disabled children. Journal of Experimental Child Psychology, 54, 372-391.

Ginsburg, H. P., Inoue, N., \& Seo, K. (1999). Young children doing mathematics: Observations of everyday mathematics. In. J. Copley (Ed.), Mathematics in the early years (pp. 88-100). Washington, DC: National Association for the Education of Young Children.

Ginsburg, H. P., \& Russell, R. L. (1981). Social class and racial influences on early mathematical thinking. Monographs of the Society for Research in Child Development, $46(6$, Serial No. 69).

Griffin, S. (2000). Number worlds: Preschool level. Durham, NH: Number Worlds Alliance.

Griffin, S. (2004). Number worlds: A research-based mathematics program for young children. In D. H. Clements \& J. Sarama (Eds.), Engaging young children in mathematics: Standards for early mathematics education (pp. 325342). Mahwah, NJ: Erlbaum. 
Griffin, S., Case, R., \& Siegler, R. S. (1994). Rightstart: Providing the central conceptual prerequisites for first formal learning of arithmetic to students at risk for school failure. In K. McGilly (Ed.), Classroom lessons: Integrating cognitive theory and classroom practice (pp. 2549). Cambridge, MA: MIT Press.

Hanich, L. B., Jordan, N. C., Kaplan, D., \& Dick, J. (2001). Performance across different areas of mathematical cognition in children with learning difficulties. Journal of Educational Psychology, 93, 615-626.

Holyoak, K. J., \& Mah, W. A. (1982). Cognitive reference points in judgments of symbolic magnitude. Cognitive Psychology, 14, 328-352.

Jordan, N. C., Huttenlocher, J., \& Levine, S. C. (1992). Differential calculation abilities in young children from middle- and low-income families. Developmental Psychology, 28, 644-653.

Jordan, N. C., Kaplan, D., Olah, L. N., \& Locuniak, M. N. (2006). Number sense growth in kindergarten: A longitudinal investigation of children at risk for mathematics difficulties. Child Development, 77, 153-175.

Jordan, N. C., Levine, S. C., \& Huttenlocher, J. (1994). Development of calculation abilities in middle- and lowincome children after formal instruction in school. Journal of Applied Developmental Psychology, 15, 223-240.

Klein, A., \& Starkey, P. (2004). Fostering preschool children's mathematical knowledge: Findings from the Berkeley Math Readiness Project. In D. H. Clements \& J. Sarama (Eds.), Engaging young children in mathematics: Standards for early mathematics education (pp. 343-360). Mahwah, NJ: Erlbaum.

Malofeeva, E., Day, J., Saco, X., Young, L., \& Ciancio, D. (2004). Construction and evaluation of a number sense test with Head Start children. Journal of Education Psychology, 96, 648-659.

McClelland, J. L., \& Elman, J. L. (1986). Interactive processes in speech perception: The TRACE model. In J. L. McClelland, D. E. Rumelhart, \& the PDP Research Group (Eds.), Parallel distributed processing: Exploration in the microstructure of cognition. Vol. 2. Psychological and biological models (pp. 58-121). Cambridge, MA: MIT Press.

Mix, K. (2002). The construction of number concepts. Cognitive Development, 17, 1345-1363.

Opfer, J., \& Siegler, R. S. (2007). Representational change and children's numerical estimation. Cognitive Psychology, 55, 169-195.

Sarama, J. (2004). Technology in early childhood mathematics: Building Blocks as an innovative technologybased curriculum. In D. H. Clements \& J. Sarama (Eds.), Engaging young children in mathematics: Standards for early mathematics education (pp. 361-375). Mahwah, NJ: Erlbaum.

Sarama, J., \& Clements, D. H. (2002). Learning and teaching with computers in early childhood education. In O. N. Saracho \& B. Spodek (Eds.), Contemporary perspectives in early childhood education (pp. 171-219). Greenwich, CT: Information Age Publishing.
Saxe, G. B., Guberman, S. R., \& Gearhart, M. (1987). Social processes in early number development. Monographs of the Society for Research in Child Development, 52(2, Serial No. 216).

Schaeffer, B., Eggleston, V. H., \& Scott, J. L. (1974). Number development in young children. Cognitive Psychology, 6, $357-379$.

Secada, W. G., Fuson, K. C., \& Hall, J. W. (1983). The transition from counting-all to counting-on in addition. Journal for Research in Mathematics Education, 14, 47-57.

Seo, K., \& Ginsburg, H. P. (2004). What is developmentally appropriate in early childhood mathematics education? Lessons from new research. In D. H. Clements \& J. Sarama (Eds.), Engaging young children in mathematics: Standards for early mathematics education (pp. 91-104). Mahwah, NJ: Erlbaum.

Shepard, R. N., Kilpatric, D. W., \& Cunningham, J. P. (1973). The internal representation of numbers. Cognitive Psychology, 6, 82-138.

Siegler, R. S. (1988). Strategy choice procedures and the development of multiplication skill. Journal of Experimental Psychology: General, 117, 258-275.

Siegler, R. S., \& Booth, J. L. (2004). Development of numerical estimation in young children. Child Development, 75, 428-444.

Siegler, R. S., \& Laski, E. V. (2007). Young children's logarithmic representations of numerical magnitude: What's the source? Manuscript submitted for publication.

Siegler, R. S., \& Opfer, J. (2003). The development of numerical estimation: Evidence for multiple representations of numerical quantity. Psychological Science, 14, 237-243.

Siegler, R. S., \& Ramani, G. B. (in press). Playing board games promotes low-income children's numerical development. Developmental Science.

Starkey, P., Klein, A., \& Wakeley, A. (2004). Enhancing young children's mathematical knowledge through a pre-kindergarten mathematics intervention. Early Childhood Research Quarterly, 19, 99-120.

Stevens, J. P. (1992). Applied multivariate statistics for the social sciences (2nd ed.). Hillsdale, NJ: Erlbaum.

Stevenson, H. W., \& Newman, R. S. (1986). Long-term prediction of achievement and attitudes in mathematics and reading. Child Development, 57, 646-659.

Stipek, D. J., \& Ryan, R. H. (1997). Economically disadvantaged preschoolers: Ready to learn but further to go. Developmental Psychology, 33, 711-723.

Thelen, E. (1996). Time-scale dynamics and the development of an embodied cognition. In R. F. Port \& T. vanGelder (Eds.), Mind as motion: Exploration in the dynamics of cognition (pp. 69-100). Cambridge, MA: MIT Press.

Whitehurst, G. J., Arnold, D. S., Epstein, J. N., Angell, A. L., Smith, M., \& Fischel, J. E. (1994). A picture book reading intervention in day care and home for children from low-income families. Developmental Psychology, 30, 679-689.

Wilson, M. (2002). Six views of embodied cognition. Psychonomic Bulletin and Review, 9, 625-636. 